\title{
HISTORIOGRAFÍA DE LA ARQUEOLOGÍA COMO NUEVA CORRIENTE DE INTERPRETACIÓN. EL SIGLO XIX EN CÓRDOBA
}

\author{
Manuel DELGADO TORRES
}

\section{Resumen}

La historiografia como corriente de interpretación desde la que abordar la historia de una disciplina posee una larga tradición. La Arqueología española, aunque tarde, se ha incorporado con fuerza a dicho movimiento. Desde estas páginas trataremos de introducirnos brevemente en el contexto sociocultural en el que a finales del siglo XIX nacerán la prehistoria y la arqueología hispanas. Para facilitar la argumentación trabajaremos en tres niveles de análisis, nacional, regional y provincial.

\section{Summary}

The historiography as a current of interpretation, to tackle the history of a discipline from, has a long tradition. Spanish archaeology, although late, has been incorporate to this movement with force. We will concisely try, to introduce us into the sociocultural context in which the Prehistory and the Hispanic archaelogy will spring at the end of the 19 th century. In order to facilite the line of argument, we will work in three levels of analysis, national, regional and provincial.

... las memorias de la antigüedad son las demostraciones verídicas de lo que fueron las gentes en los tiempos a que se refieren: por ellas viene a averiguarse lo que alcanzaron, el modo en que se manejaron, su gobierno y economia; y a este respecto lo que han adelantado o perdido, lo numeroso de sus gentios, la indastria, el valor y las máximas de manejarse: sin los monumentos, que sin embargo de la ruina de los tiempos se conservan en alguna parte, no habria documentos formales de donde inferirlo.

(Antonio de Ulloa, 1772, Noticias Americanas) 
Las innovaciones teóricas que desde los años ochenta, y a un ritmo acelerado, ha experimentado la Arqueología española, forman parte de una renovación metodológica que, reciente, aún está por historiar. Dicha renovación se ha sustentado en un ataque incruento pero frontal contra todo lo anterior. De modo que un amplio sector de la investigación abandonó el tortuoso camino del positivismo y el enfoque histórico-cultural para acogerse, como una nueva luz, a alguna de las corrientes que ya desde algunos años antes se desarrollaban en Europa.

Esta bocanada de aire fresco desterró para siempre de su lenguaje y práctica todos aquellos elementos que desde el siglo XIX, y con pocas variaciones, formaban el cuerpo doctrinal de la arqueología española. Así, el arqueólogo español sufrió una suerte de catarsis que transformó al erudito investigador, confinado en la universidad y sumergido en la «mugre» de la cerámica, en un abanderado de la Nueva Arqueología, los procesos post-deposicionales, el lenguaje procesual y la arqueología marxista o estructuralista. Demostrando, tal y como nos dijo Georges Daux, que «antes de llegar a ser una ciencia la arqueología es una actitud» (DAUX, 1948, 18)).

Este proceso fue consecuencia lógica del amplio cambio social, económico, político y cultural que España vivió en los ochenta. Se abandonó el pesado lastre que para la investigación y la Universidad tuvo la dictadura, acogiéndose con esperanza los aires de apertura a Europa que la democracia trajo consigo. Se demostraba, de esta forma, que la investigación arqueológica está influida por diferentes tipos de factores, entre los cuales el contexto social resulta determinante.

Sin embargo, nuestra intención no es analizar esa renovación teórica y metodológica. Demasiado pretencioso. Nos conformamos con reivindicar, dentro del proceso antes mencionado, la necesidad para el arqueólogo de historiar su disciplina, de volver la mirada atrás. Todo ello bajo un enfoque histórico, ya que éste «ofrece una posición especialmente ventajosa desde la cual poder examinar las relaciones cambiantes entre la interpretación arqueológica y su medio social y cultural». (TRIGGER, 1992, 15).

Así, desde principios de los noventa, numerosos arqueólogos e historiadores han utilizado la perspectiva histórica para examinar el desarrollo de la interpretación arqueológica en España durante los siglos XIX y XX. Tesis Doctorales, (AYARZAGÜENA, 1992), (JIMÉNEZ DÍEZ, 1993), Congresos, Cursos y Conmemoraciones (ARCE, OLMOS, 1991), (BELTRÁN, GASCO, 1994, 1995), (MARCOS POUS, 1993) y un notable número de artículos configuran un «boom» historiográfico que intenta colmar el vacío anterior.

Sin embargo, nuestra labor va más allá de la subjetividad de la interpretación histórica; no se trata de trazar un camino lineal y aséptico por el cual discurra la historia de la arqueología española. El desarrollo historiográfico debe adquirir un marchamo de compromiso intelectual y científico que huya de la acumulación biblio- 
gráfica para adentrarse en el mundo de los «nombres, escuelas e influencias» (AR$\mathrm{CE}, 1988,17)$. No debemos olvidar que la historia de la arqueología es, ante todo, una historia de ideas, de formas y modos de entender el pasado.

De este modo, ciñéndonos a la segunda mitad del siglo XIX, nuestra exposición comenzará con una descripción del contexto global en el que surgen la prehistoria y la arqueología españolas, para luego, dentro de esa estructuración, mostrar cuál ha sido la aportación cordobesa. Veámoslo.

EI XIX español es una historia permanente de fracasos y frustraciones. El triunfo del Liberalismo con la imposición del sistema político de la Restauración no enmascara la base corrupta en la que se apoyaba. Fracaso que sin solución de continuidad se prolongará en el XX con la dictadura de Primo de Rivera, la guerra civil y el régimen franquista.

A pesar de todo, como un ave fénix, el liberalismo español mostró una asombrosa capacidad de sobrevivir. En un mar de guerras civiles, corruptelas, caciquismo, y pronunciamientos, el siglo XIX encontró un punto de inflexión en 1868. La "Gloriosa» Revolución de Septiembre supuso la apoteosis del progresismo y dio lugar a un período de febril actividad reformista. Sin embargo, Antonio Cánovas del Castillo, el primer cirujano de hierro de la historia política española, borró de un plumazo con su «turno pacífico» la época de los pronunciamientos y cualquier intento de régimen democrático, inaugurando el sistema de la Restauración.

De nuevo el estancamiento político. Y a su imitación el económico y social. Un país con una población mayoritariamente agraria, analfabeta, manipulada por las élites locales. Una demografía en plena transición, aquejada por grandes mortandades catastróficas, producidas por hambres y epidemias. Un escaso crecimiento económico que mantuvo a la mayoria de la población española en la pobreza y la ignorancia. $\mathrm{Y}$ en ese contexto, el triunfo de las clases medias, de la burguesía y las élites urbanas, aquéllas que habrían de protagonizar los inicios de la Prehistoria y Arqueología españolas.

Protagonistas que, en su intento de derribar los cimientos del Antiguo Régimen, se verán arrastrados por la corriente arrolladora del nacionalismo emergente y a través del concepto de Estado-nación formarán la nueva base social que arrebate a nobles y eclesiásticos la primacía de los estudios históricos. En ese instante, Arqueología y Prehistoria conocen caminos separados. Intentaremos desbrozar cada uno de ellos.

Desde el Renacimiento, la Arqueología era sinónimo de anticuarismo. De este modo, junto a los textos escritos comenzaron a ser considerados aquellos restos materiales supervivientes del pasado clásico en un intento de recoger, comprender e 
imitar los gloriosos logros de la Antigüedad. Se trataba de revalorizar el presente mediante el recuerdo didáctico de un pasado que se torna ejemplificador.

Salvado el bache que para la formación de una historia nacional supuso el período de los «falsos cronicones» (CARO BAROJA, 1992), y abandonada la perspectiva de un relato histórico exclusivamente eclesiástico y militar, durante el siglo XVIII, tras diversos avatares que incluyen la instrumentalización política de la Arqueología por parte de la Monarquía borbónica (MORA, 1991), la creación de las primeras Academias, Sociedades y Colecciones ilustradas y las primeras excavaciones (FERNÁNDEZ MURGA, 1962, 1988), (REPRESA, 1987), (NEGUERUELA, 1993, 246-254), la arqueología clásica española se encontraba, en el último tercio del siglo XIX, lastrada por lo que Mélida denominaba «arqueología de gabinete» (ALMELA BOIX, 1991, 131). Consistente en una acumulación de datos epigráficos, numismáticos, escritos, etc... de cuya acumulación positivista surgiría la historia.

Esta concepción anticuaria de la arqueología adq̣uiriría marchamo de institucionalización con la creación el 7 de octubre de 1856 de la Escuela de Diplomática. Hasta la fecha, la Real Academia de la Historia era la auténtica depositaria del saber erudito $y$, sus miembros, guardianes de una historia que ahora pretendía servir a las exigencias del Estado liberal. La erudición definida como, «...colección de saberes e intereses dispersos acumulados con ambición, y que raramente se apoyaban en unos conocimientos técnicos», se convertirá en el sello cultural de la burguesía española. La formación a través de la Escuela de un concepto profesional de la erudición creará un modelo de historia y cultura oficial que, partiendo de la capital del Estado, irradiará su influencia al conjunto de las capitales de provincia españolas por medio de un ejército de funcionarios (PASAMAR, PEIRO, 1991, 73-74).

Hasta su supresión por R.D. de 20 de Julio de 1900 la Escucla Superior de Diplomática conservará en los estudios de Arqueologia el valor artístico y anticuario. La misión de sus miembros consistirá en «recuperar y custodiar las antigüedades y organizar el patrimonio artístico y literario nacional». (PASAMAR, PEIRO, 1991, 74). El término arqueología, en una larga tradición Winckelmaniana, «incluye lo que ahora consideraríamos arqueología de la época clásica a la moderna, asi como la historia del arte de estos mismos períodos». (DÍAZ-ANDREU, MORA, 1995, 29). Vivero de numerosos arqueólogos y eruditos, la Escuela, cederá en 1900 sus miembros y cátedras a una institución emergente, la Universidad.

Otro de los hitos fundamentales en la historia de la Arqueología española es la fundación el 20 de Marzo de 1867 del Museo Arqueológico Nacional. Fruto de la preocupación del Estado burgués por crear una identidad nacional, las colecciones del M.A.N., despojadas de su tributo Real, servirán de instrucción pública para un pueblo que recupera un pasado común. 
Su personal, surgido de las filas del Cuerpo Facultativo de Archiveros, Bibliotecarios y Anticuarios, y sus actividades convertirán al M.A.N., durante el último tercio del siglo XIX, en la cabeza visible de la recuperación y catalogación del patrimonio (MARCOS POUS, 1993). Las Comisiones científicas que por encargo del M.A.N. recorrerán España entre 1868 y 1875 (FRANCO MATA, 1993, 300-309), el viaje al Oriente mediterráneo en el verano de 1871 de la fragata Arapiles (CHINCHILLA, 1993, 271-275), representan el trasunto público de un más amplio interés por la arqueología y la antigüedad, interés materializado en la novela histórica (OLMOS, 1992, 52-57) o la pintura de historia (QUESADA, 1994, 36-47).

Así pues, al finalizar el siglo España cuenta con las instituciones necesarias para la custodia del patrimonio, el cuerpo profesional encargado de llevarlo a cabo y de los órganos que como, Museo Español de Antigüedades y Revista de Archivos, Bibliotecas y Museos tenían como responsabilidad su divulgación. Pero la tradición era rabiosamente clásica, ajena a los progresos que en la evolución y origen del hombre había establecido la prehistoria. «Este hecho estaba basado en la creencia compartida por los arqueólogos clásicos de que el conocimiento histórico podía ser adquirido exclusivamente a través de documentos escritos o tradiciones orales mínimamente fiables y que si no se disponía de ellos no era posible conocer los tiempos más antiguos. La creación de la arqueología prehistórica requirió que los anticuarios hallasen los medios para liberarse de esa restrictiva convicción». (TRIGGER, 1992, 76).

Sin embargo, en nuestro país, arqueólogos y anticuarios -léase eruditos-se vieron exonerados de tan "penosa» tarea. El desarrollo de la ciencia prehistórica estuvo en manos de hombres que nunca habían pisado la Escuela Superior de Diplomática y que lejos de la formación humanística que tanto ésta como el Cuerpo Facultativo otorgaban, descubrieron la prehistoria a través de las Ciencias Naturales. Hay que recordar que la distancia que hoy consideramos diáfana entre la geología y la paleontología de un lado y la arqueología de otro, en los siglos XVIII y XIX no era tal y todas formaban parte de ese cajón de sastre que era la Historia Natural.

El nacimiento de la arqueología prehistórica se fundamentaba en dos conquistas básicas: el establecimiento de un sistema de cronología relativa coherente y la evidencia firme de la antigüedad del hombre. La ordenación de los materiales depositados en el nuevo Museo Nacional de Antigüedades de Copenhague motivó el establecimiento por parte de Christian Jurgensen Thomsen del «Sistema de las Tres Edades», una sencilla idea basada en la ordenación, piedra, bronce y hierro. Tanto los resultados de sus investigaciones en el Museo danés, publicados en 1836 con el título Ledetraad til Nordisk Oldkyndighed (Guía de Antigüedades Escandinavas), como la labor arqueológica de campo de Jens Worsaae, hicieron posible que la arqueología prehistórica se desarrollase en Escandinavia antes de 1859 «como una disciplina bien definida" (TRIGGER, 1992, 87). 
Junto al núcleo escandinavo, Francia e Inglaterra contaron desde los inicios del siglo XIX con un grupo de investigadores que, no sin dificultades y adscritos a lo que se llamaría Arqueología del Paleolítico, armarían el edificio doctrinal del que surgiría el reconocimiento de la antigüedad del hombre. Se lograba así cuestionar la cronología bíblica, concediendo una profundidad hasta entonces insospechada a la cronología del pasado de la humanidad.

Sin embargo, el desarrollo de la Arqueología Prehistórica o Paleolítica no adquiriria carácter científico en Francia ni en Inglaterra antes de finales de la década de 1850. Con todo, su auge fue consecuencia de la aparición de la perspectiva evolucionista en Geología y Paleontología. En la primera mitad del XIX la proliferación de hallazgos en los que aparecían asociados restos humanos, instrumentos de piedra y huesos de animales extinguidos creó el ambiente necesario para cuestionar aquellas teorías que como la del Diluvio Universal vertebraban la cronología imposible de la humanidad.

Las investigaciones de MacEnery en Kent's Cavern (Inglaterra), o las de Boucher de Perthes en el valle del Somme (Francia), representaban a pesar de la obstinación de los círculos más conservadores, reacios a admitir cualquier cambio que modificara su estrechez religiosa de miras, un peldaño más en la escala ascendente de los estudios prehistóricos. Refrendo definitivo a la labor de los dos denostados naturalistas fue la publicación, entre 1830 y 1833, de Principles of Geology a cargo de Charles Lyell, inaugurando la visión «uniformista» de la historia geológica (HARRIS, 1991, 25-26; DANIEL, 1968, 31-32).

Así las cosas, en el verano y la primavera de 1859 Prestwich, Evans y Lyell otorgaban a pie de yacimiento validez científica a los hallazgos de Boucher de Perthes, confirmando la considerable antigüedad del hombre. Por si fuera poco en noviembre de ese mismo año Charles Darwin publicaba El origen de las Especies. La idea darwiniana, ampliada por Huxley, de una compleja evolución física y cultural del hombre, encendió el debate en Europa, dividiendo la comunidad científica en evolucionistas y creacionistas.

A partir de 1860, la arqueología prehistórica, impregnada de evolucionismo, dedicó todas sus energías a la ordenación cronológica de los yacimientos. Con una sólida formación geológica y paleontológica, primero Edouard Lartet y luego Gabriel de Mortillet crearon la primera secuencia cronológica de una Edad de la Piedra que en 1865 el banquero y político John Lubbock, en su libro Prehistoric Times, había dividido en Paleolítico y Neolítico.

Constituye un lugar común recordar el proverbial atraso en que, con respecto a los acontecimientos que acabamos de narrar, se encontraba la Península Ibérica. Bien 
es verdad que en un país aislado durante décadas, fiel a la ortodoxia católica y por lo tanto lleno de prejuicios religiosos, con una educación y cultura sólo accesible a las élites, resulta lógico que los estudios acerca de la antigüedad y origen de la humanidad no gozaran de un ambiente proclive a su desarrollo. Sin embargo, todo eso no excluye que ya en fechas muy tempranas unos pocos hombres se sintieran atraídos por una ciencia novedosa en concepción y metodología.

Esos hombres encontraron entre 1868 y 1875 el ambiente proclive al desarrollo de una mentalidad científica, pasando en ese intervalo de tiempo desde las posiciones metafísicas idealistas del krausismo a la nueva mentalidad positiva (KAPLAN, 1970, 254-266), que a la postre favorecerá el desarrollo de la Ciencia Natural de mediados de siglo. En efecto, la libertad de expresión generada por la Septembrina constituirá la antesala para la posterior efervescencia intelectual de la Restauración.

El positivismo -recordemos que el XIX es el siglo de los hechos- y el evolucionismo/transformismo constituyen el marco de actuación en el que nacerá la arqueología prehistórica española. La llegada a nuestro país de las teorías evolucionistas (GLICK, 1970, 267-272) resulta trascendental, y el deseo de conciliar los principios de la fe con la evidencia del origen y la antigüedad del hombre dividirá posturas, apasionadamente defendidas en Ateneos y Sociedades. Todo lo cual, no enmascara la falta de originalidad en los posicionamientos hispanos o la fractura social a que dará lugar el nuevo orden intelectual (NÚÑ̃EZ, 1975, 19-24).

En esta coyuntura, el devenir de la prehistoria española podría sistematizarse de la siguiente forma:

- primeros balbuceos en los años iniciales de la segunda mitad del siglo XIX. En 1846, Juan Ximénez de Sandoval, Marqués de la Ribera, encargado de negocios de la embajada española en Copenhague, elabora su Catálogo de la colección escandinava de instrumentos, de piedra y de cobre, que D. Juan Ximénez de Sandoval, Marqués de la Ribera, regaló en 1847 al Museo Nacional de Antigüedades de Madrid, hallándose de representante de España en Dinamarca. Una obra impregnada de los avances que por aquella época hacían de Dinamarca el centro de la arqueología prehistórica europea (SUÁREZ OTERO, 1993, 326-329), En los primeros años de 1850, Casiano del Prado (AYARZAGÜENA, 1990b, 8-10) inicia la serie de investigaciones por la geografía madrileña que culminarán en 1860 con la visita de Lartet y Verneuil al yacimiento de San Isidro, versión española de las terrazas del Somme.

- protagonismo, como en el resto de Europa, de las Ciencias Naturales, Geología, Paleontología, en la definición y nacimiento de los estudios prehistóricos, constreñidos en ese momento en círculos intelectuales restringidos, como la Sociedad Antropológica Española (1865) y la Sociedad Española de Historia Natural (1871).

- a partir de 1866, inicio de la actividad investigadora de Juan Vilanova y Piera (AYARZAGÜENA, 1990c, 40-43), padre por muchos conceptos de la prehistoria es- 
pañola, cuyo ejemplo de trabajo individual, sin apoyo oficial, puede trasladarse a todos aquellos que por la misma época cultivan esta clase de estudios.

- existencia de dos modelos de estudio, diferenciados conceptual e ideológicamente. Por un lado, el erudito, confinado en las dependencias de la Real Academia de la Historia, el Museo o posteriormente la Universidad, y por otro el naturalista, dividido a su vez en creacionistas (Vilanova) y evolucionistas (Tubino) (AYARZAGÜENA, 1990a, 21).

- punto de inflexión en la década de 1880 con la publicación por parte de Marcelino Sanz de Sautuola (PUMAJERO, 1990, 54-56) de las pinturas rupestres de Altamira, que encienden una viva polémica hasta principios de siglo y el nombramiento de Juan Vilanova como académico de la historia, hecho que supondrá el reconocimiento oficial de la nueva ciencia.

De esta manera, a principios del siglo XX, parecen establecidas las bases de una arqueología afín al movimiento europeo, con metodologia ciertamente rudimentaria pero con una sólida formación teórica. Los distintos vaivenes por los que atravesará la realidad social y política española abortarán la virtualidad de esos intentos embrionarios de homologación.

La respuesta andaluza al debate conceptual e ideológico antes mencionado fue desde un principio clara y contundente. La región se iba a convertir, a pesar de lo que su retraso social y económico hacía preveer, en uno de los primeros focos de nacimiento y difusión de los nuevos estudios prehistóricos. No en balde muchos de los grandes nombres de la arqueología y prehistoria decimonónica son en buena parte andaluces.

Desde la segunda mitad del siglo XIX, Sevilla se alzará como uno de los núcleos intelectuales más dinámicos. Antonio Machado y Núñez ofrece ya en 1843, siguiendo a Lyell, un curso de Geología. En 1860, desde su cátedra de Historia Natural de la Universidad de Sevilla introducirá por primera vez en España el evolucionismo de Darwin. Adherido con entusiasmo a los principios revolucionarios de 1868 , al año siguiente fundará con Federico de Castro, reputado krausista, La Revista de Filosofía, Literatura y Ciencias, que a lo largo de sus seis años de existencia dará cabida a los personajes y teorías protagonistas del renovado pensamiento científico y filosófico peninsular. De igual forma, en 1871 fundará la Sociedad Antropológica Sevillana donde se formarán positivistas como Francisco M. Tubino y Manuel Sales y Ferré.

Francisco M. Tubino (AYURZAGÜENA 1994, 42-45), periodista crítico de arte e historiador se nos presenta como un caso particular. Si por su formación pertenece al modelo de estudio erudito, sin embargo, su práctica intelectual lo convertirá en 
uno de los principales exponentes del evolucionismo y de la ciencia positiva. Con una producción bibliográfica inagotable, en 1867 Tubino fue el primero en utilizar en castellano la palabra "prehistoria" en las páginas de su periódico La Andalucía. Fundador de la Revista de Bellas ARtes e Histórico-Arqueológica, pese a la brevedad de su publicación (1866-1868), su estudio es indispensable para entender el desarrollo de la arqueología prehistórica en nuestro país.

A pesar de mantener posturas diferentes respecto al origen del hombre, gran parte de su labor la desarrolló al lado de Vilanova, acompañándolo en diversas prospecciones por Sevilla, Cerro Muriano o Cabra (Cuevas de Zarcas), y participando con el sabio valenciano en el Congreso Internacional Prehistórico celebrado en Copenhague en 1869 (SUÁREZ OTERO, 1993, 329-333). Ya en solitario, hay que destacar los trabajos de excavación e interpretación que llevó a cabo en la Cueva de la Pastora (Valencina de la Concepción, Sevilla) (BELÉN, 199I, 7-15).

Junto a ellos podríamos destacar a Manuel Sales y Ferré. Catedrático de Historia Universal en la Universidad de Sevilla y desde 1898 de Sociología en la Facultad de Filosofía y Letras de Madrid, quien en 1880 publicó Prehistoria y Origen de la Civilización, donde se muestra como un apasionado defensor del evolucionismo en la prehistoria, la antropología y la sociología; al geólogo Salvador Calderón Arana y su labor en la sección sevillana de la Sociedad de Historia Natural; a Manuel Medina Ramos y sus estudios palcoantropológicos y por último a Francisco de las Barras de Aragón (AYARZAGÜENA, 1992, 774-780).

Fuera del círculo sevillano, las doctrinas transformistas y positivistas encontrarán amplio eco en el catedrático de Historia Natural del Instituto de Granada, Rafael García Álvarez o en las publicaciones Revista de Andalucía de Málaga o la Revista de Almería (NÚN̄EZ, 1975, 57-58).

Frente a los estudios prehistóricos, la arqueología andaluza discurre por los caminos de la tradición anticuaria y filológica. Desde el Renacimiento, se construirán los cimientos de un edificio conceptual que tendrá en la epigrafía un pilar de estudio fundamental (GONZÁLEZ, 1994, 64-84). El placer diletante, plasmado en la creación de numerosos colecciones (LLEÓ CAÑAL, 1995, 57-74; BELTRÁN, 1995, 105-151). El deseo de ennoblecer los orígenes de ciudades andaluzas a las que se intenta revestir del prestigio del pasado clásico, recurriendo a inscripciones inventadas, falsas crónicas o fundadores míticos (GASCÓ, 1994, 9-28). El programa de renovación ilustrada, origen de numerosas Academias y Sociedades, cuyos estudios aunaron la preocupación por la conservación del objeto o el monumento con la percepción de un pasado clásico, rico en matices económicos y culturales. Y por fin, el XIX, que con sus flujos y reflujos establecerá las bases de una arqueología empírica inalterada hasta bien entrado nuestro siglo. 
Una arqueología andaluza decimonónica que podríamos caracterizar de esta forma:

a) Preocupación por el valor intrínseco del objeto, descontextualizado, entre una acumulación plácida de pruebas epigráficas, numismáticas, históricas, que prueben la localización de vías y especialmente ciudades antiguas, contribuyan a la reducción geográfica de famosos campos de batalla o a la catalogación de las antigüedades dispersas por el solar andaluz.

b) El inicio de una preocupación más honda por la conservación y protección del objeto inmueble. Todo ello gracias a la creación de nuevas instituciones y a la elaboración de un cuerpo legislativo en defensa del Patrimonio. A este deseo responde la labor tutelar de las Academias -ya sean la de Historia, la de Bellas Artes de San Fernando y a su amparo las provinciales-, la creación de los Museos Arqueológicos o la legislación que acompaña al establecimiento de las Comisiones Provinciales de Monumentos Históricos y Artísticos.

c) La gran aportación andaluza en hombres y obras al panorama de la arqueología peninsular, trasunto del lugar preeminente ocupado por los andaluces en la vida política y cultural del siglo pasado. Manuel Oliver y Hurtado, los hermanos Amador de los Ríos, Juan de Dios de la Rada y Delgado, Aureliano Fernández Guerra y Orbe, Manuel Rodríguez de Berlanga (RODRÍGUEZ OLIVA, 1991, 99-196; PACHÓN, PASTOR, 1995, VII-XCII), Manuel de Góngora y Martínez (PASTOR, PACHÓN, 1991, VIII-LXXV; AYARZAGÜENA, 1994, 56-59), etc...

d) La llegada de investigadores extranjeros, G. Bonsor (AYARZAGÜENA, 1994, 52-57), Luis Siret (GOBERNA, 1986; AYARZAGÜENA, 1992, 1.027-1.045), Pierre Paris, Arthur Engel, que consideran Andalucía como una tierra de promisión para la investigación, Ilenando el vacío de una arqueología que fluctuaba entre el estudio del origen y antigüedad del hombre y la atracción de un pasado clásico que afloraba por doquier.

Este apretado resumen historiográfico, hasta ahora resuelto en dos niveles, nacional y regional, pretende servir de enfoque teórico en el análisis del que consideramos un tercer nivel de estudio: la arqueología provincial y local cordobesa en la segunda mitad del siglo XIX.

Córdoba vive durante toda la centuria decimonónica en estado de postración social y económica. Una decadencia, arrastrada desde el siglo XVIII, que provocará a partir de 1860 un profundo malestar social, debido a la miseria de los jornaleros, las malas cosechas, las nuevas ideologías proletarias o la intensificación del bandolerismo. En ese contexto, la lucha por la tierra se convertirá en el problema central del campesino cordobés, mal nutrido, analfabeto y con salario y vida miserables. 
La agricultura, lastrada por el predominio de la gran propiedad nobiliaria y eclesiástica y con un escaso grado de aplicación técnica y un anticuado sistema de cultivo, constituye el soporte básico de la economía cordobesa. Junto a ella, una industria testimonial, cuyo paradigma es la Casa Carbonell y su comercialización del aceite, y las grandes esperanzas de la explotación minera y el ferrocarril, en última instancia frustradas por lo que podríamos llamar la «traición» del capital extranjero (CASTEJÓN, 1981).

Con estas bases de partida, en 1877, de 385.582 habitantes provinciales sólo 69.006 sabían leer y escribir, producto de una Instrucción Primaria en situación desoladora (CASAS SÁNCHEZ, 1992, 150), y una Enseñanza Superior inexistente si exceptuamos la experiencia de la Universidad Libre entre 1870 y 1874 (ARANDA, 1974). Así, durante todo el período de la Restauración la vida de los cordobeses discurrirá plácidamente, ajena a grandes acontecimientos, con una burguesía agraria de escasa afición a la actividad intelectual.

Sin embargo, a pesar de esta atonía cultural, existe un hecho cierto: el permanente diálogo de la ciudad con su pasado. A través de él surgirá la imagen de una Córdoba exótica y oriental que atrae con entusiasmo a los viajeros románticos del siglo XIX (LÓPEZ ONTIVEROS, 1991), responsables en la creación de una oposición, ya clásica; el esplendor de su historia árabe y la decadencia contemporánea. Un diálogo que continúa hoy en día proporcionando pruebas de una inmensa riqueza arqueológica (CARRILLO, MÁRQUEZ, MURILLO, VENTURA, 1995) que la modernidad del «progreso» pretende convertir en pesado lastre para el desarrollo. De cualquier forma, se pueden establecer dos características básicas de la arqueología cordobesa deI XIX que apenas modificadas llegan hasta nuestros días: la escasa repercusión de la arqueología prehistórica y la línea historicista en el estudio de la antigüedad.

Respecto al primer punto, podemos decir que la provincia permanece al margen del debate intelectual que a partir de 1868 genera el desarrollo de la arqueología prehistórica en nuestro país. No existe ninguna personalidad que desde el campo de las ciencias naturales o la erudición asuma la novedad de los estudios prehistóricos. Poco más que la visita en 1867 de Vilanova y Tubino a los yacimientos de Cerro Muriano y Cueva de Zarcas en Cabra, las noticias aisladas sobre descubrimientos de objetos prehistóricos en las numerosas historias locales que surgen en el último tercio del siglo o la actuación aislada de algún erudito local, como Agustín Pérez de Siles, a cuyo cargo corrió la presentación oficial de la Ciencia Prehistórica en la Real Academia de la Historia en la sesión de 7 de Junio de 1867 (AYARZAGÜENA, 1992, 170).

En cuanto a la segunda característica, parece erigirse en una constante histórica. Se funda en una larga tradición que comienza con el protagonismo de los estudios 
anticuarios y epigráficos de Ambrosio de Morales y Juan Fernández Franco en el siglo XVI, continuados en el XVII y XVIII por la actitud coleccionista de Bernardo de Cabrera, Pedro Díaz de Rivas, Enrique Vaca de Alfaro o el marqués Pedro Leonardo de Villaceballos (BELTRÁN, 1994, 113-122). El siglo XIX institucionalizará esa posición en los trabajos de los miembros de la Academia de Ciencias, Bellas Letras y Nobles Artes y las actuaciones de la Comisión Provincial de Monumentos Histórico y Artísticos. De ese modo, el historicismo impregnará las dos líneas recurrentes de la antigüedad cordobesa, el pasado clásico y el pasado árabe. La concreción material de estos principios estará protagonizada, entre otros, por hombres como Luis M. Ramírez de las Casas Deza, símbolo de la erudición cordobesa, autor entre otras obras del Indicador cordobés o los Anales de la Ciudad de Córdoba; Rodrigo Amador de los Rios, que siguiendo la tradición familiar de los estudios históricos dedicará una extensa producción bibliográfica a la Córdoba musulmana destacando su Inscripciones árabes de Córdoba, precedido de un estudio crítico de la Mezquita-Aljama; Rafael Romero Barros, cuya dedicación a la arqueología árabe se materializó en numerosos artículos y noticias publicadas en el «Diario Córdoba»; Luis Maraver y Alfaro, cronista de la ciudad y primer excavador de los yacimientos ibéricos de Fuente Tójar y Almedinilla (MARAVER, 1866-67); Enrique Romero de Torres, Francisco de Borja Pavón, ambos ligados a la vida del Museo Arqueológico Provincial o Ricardo Velázquez Bosco, unido indisolublemente a los dos más importantes monumentos árabes cordobeses, la Mezquita-Aljama y la ciudad de Medina Azahara.

La labor de la Comisión Provincial, objeto de una reciente publicación (PALENCIA, 1995) constituye una vía de acceso privilegiada a la historia de la arqueología cordobesa. A través de su Archivos accedemos a una serie de hitos, de entre los cuales podríamos destacar:

- los diversos avatares que guían la tutela del patrimonio cordobés a raíz del proceso desamortizador. Como en otros lugares del país estos intentos de secularización y estatalización del patrimonio, en otro tiempo en manos eclesiásticas, estarán marcados por una suerte de despropósitos que impedirán el trabajo de las Comisiones.

- los trabajos de los diversos corresponsales provinciales de la Comisión.

- las peripecias de la misión militar franco-española que en sus deseos de identificar los escenarios de las Guerras Civiles lleva a cabo excavaciones en la zona de Montilla y Espejo en 1863 y 1865 (MARCOS POUS, 1993, 43; GRAN AYMERICH, 1991, 117; PALENCIA, 1995, 88).

- la constitución en 1867 del Museo Arqueológico Provincial (SANTOS GENER, 1950, 7-21).

- la expedición arqueológica a los yacimientos iberorromanos e ibéricos de Fuente Tójar y Almedinilla por parte del conservador del Museo, Luis Maraver y Alfaro (VICENT, 1984-85, 31-55; VAQUERIZO, 1990, 63-73; PALENCIA, 1995, 86- 
87). Hombre de carácter controvertido, que tuvo no pocos enfrentamientos con otros miembros destacados de la Comisión Provincial.

- la proliferación de hallazgos arqueológicos urbanos, particularmente intensa a partir de 1870 , en relación con la remodelación urbana de la ciudad, siguiendo los preceptos higienistas del Estado burgués (MARTÍN LÓPEZ, 1990; GARCÍA VERDUGO, 1992).

- la relación entre arquitectura y arqueología, ya puesta de manifiesto para otros ámbitos (BELTRÁN, 1995, 34-45), protagonizada por la emblemática Mezquita, la Sinagoga judía, los baños califales, la ciudad de Medina Azahara, el templo romano, etc...

Frente a la actividad provincial; una multitud de eruditos locales, muchas veces olvidados e ignorados, cuya pasión por la historia, fenómeno generalizado en el XIX, dio lugar a un número inusual de producciones locales (MORENO ALONSO, 1976, 127-135; 1979), hoy estudiadas para el caso cordobés (CASAS SÁNCHEZ, 1992). Según Casas Sánchez, todas estas obras participan de una serie de rasgos comunes que podrían resumirse de esta manera:

1. Su contenido. Importancia a la antigüedad y menos a la época musulmana. Con ello encontramos un punto de desencuentro frente a la actitud de los eruditos de la capital, imbuídos del pasado musulmán de la ciudad.

2. Doble localismo: el del objeto de estudio y el del lector al que se dirigen.

3. En cuanto a su aparición, esta eclosión de la historiografía local coincide con un florecimiento de la prensa, uno de los elementos que contribuirán al desarrollo del localismo, entendido como exaltación de lo propio (CASA SÁNCHEZ, 1992, 120, ss.).

Uno de los núcleos provinciales donde se hace patente este amor a la historia y con ella a todo lo referente al pasado, es Puente Genil. Desde el último tercio del siglo XIX este pueblo experimenta una transformación socioeconómica que lo convierte en uno de los enclaves de mayor dinamismo comercial e industrial de Córdoba. El municipio pontanés no sólo vivía años de bonanza económica. Los 9.479 habitantes de 1890 gozaban de dos bibliotecas, dos teatros y dos revistas literarias editadas en el propio municipio, amén de un elenco de personajes que destacaban en el terreno de la literatura, la política, la historia. A escala local este ambiente representa el cambio que desde la "Revolución de 1868» se experimenta en el panorama intelectual español.

Figura emblemática de este movimiento provincial, es Antonio Aguilar y Cano (DELGADO TORRES, 1995), arqueólogo e historiador de reconocido prestigio cuya trayectoria refleja las virtudes y defectos de la formación erudita. Muchos de estos hombres constituyen pieza fundamental en la formulación teórica de nuestra 
ciencia y aún hoy referencia ineludible en muchos estudios. Tratar de «desenterrar» ese pasado es hoy tributo merecido a quienes abrieron caminos todavía intransitados'.

\section{BIBLIOGRAFÍA}

ALMELA BOIX, A. (1991): «La aportación de José Ramón Mélida a la consolidación de la Arqueología como disciplina científica en España», en J. Arce y R. Olmos (coords.), pp. 131-134.

ARANDA DONCEL, J. (1974): La Universidad de Córdoba, Córdoba.

ARCE, J. (1988): España entre el mundo antiguo y el mundo medieval, Ed. Taurus.

ARCE, J.; OLMOS, R. (coords.) (1991): Historiografía de la Arqueología y de la Historia Antigua en España (siglos XVIII-XIX), Ministerio de Cultura, Madrid.

AYARZAGÜENA SANZ, M. (1990a): "Orígenes de la Arqueología Prehistórica en España», Revista de Arqueología 105, Madrid, pp. 16-24.

- (1990b): «Casiano del Prado y Vallo. Introductor de los estudios prehistóricos en España», Revista de Arqueología 107, Madrid, pp. 7-10.

- (1990c): «Juan Vilanova y Piera. Padre de la Prehistoria Española», Revista de Arqueología 108, Madrid, pp. 40-43.

- (1992): La arqueología prehistórica y protohistórica española en el siglo XIX, Ed. UNED, Madrid.

- (1994a): «Manuel de Góngora y Martínez», Revista de Arqueología 153, Madrid, pp. 56-59.

- (1994b): «Francisco M. Tubino y Oliva (1834-1888)», Revista de Arqueología 156, Madrid, pp. 42-45.

— (1994c): «George Edward Bonsor (1855-1930)», Revista de Arqueología, Madrid, pp. 52-57.

BELÉN, M. (1991): «Apuntes para una historia de la Arqueología Andaluza. Francisco M. Tubino (1833-1888)». BMAN, IX, Madrid, 7-15.

BELTRÁN FORTES, J. (1994): «Entre la erudición y el coleccionismo: anticuarios andaluces de los siglos XVI a XVIII», en J. Beltrán y F. Gascó (eds. ): 105-124.

- (1995): «Arqueología y configuración del patrimonio andaluz», En F. Gascó y J. Beltrán (eds.): 105-151.

\footnotetext{
' En estos momentos bajo la dirección del Prof. Dr. Desiderio Vaçuerizo Gil nos encontramos realizando la Me. moria de Licenciatura que, con el titulo eEntre la Enadición y la profesionalización. Connexto y desarrollo de la Arqueología cordohesa durance la segunda mitad del siglo XIX". lienc como figura principal a esle erudito y arqueólogo.
} 
BELTRÁN, J.; F. GASCÓ (eds.) (1994): La Antigüedad como argumento. Historiografía de Arqueología e Historia antigua en Andalucía. Junta de Andalucía. Sevilla.

CARO BAROJA, J. (1991): Las falsificaciones de la historia (en relación con la de España). Círculo de Lectores. Barcelona.

CARRILLO, J. R. et alii (1995): "Arqueología de Córdoba", Revista de Arqueología 171, 172 y 173. Madrid.

CASAS SÁNCHEZ, J. L. (1992): Estudio de la Historiografía sobre Córdoba y provincia (1700-1936). Cajasur. Córdoba.

CASTEJÓN, R. (1981): «La economía cordobesa en su perspectiva histórica», en Córdoba, apuntes para su historia. Córdoba.

CHINCHILLA, M. (1993): «El Viaje a Oriente de la fragata Arapiles», en A. Mar$\cos$ (coord.): 286-294.

DAUX. G. (1948): Les étapes de l'Archéologie. París.

DANIEL, G. (1968): El Concepto de Prehistoria. Ed. Labor, Barcelona.

DELGADO TORRES, M. (1995): «Breve historiografía de la investigación arqueológica en Puente Genil: siglos XIX y XX», Revista El Pontón 102 y 103. Puente Genil.

DÍAZ-ANDREU, M.; MORA, G. (1995): «Arqueología y Política: el desarrollo de la Arqueología española en su contexto histórico», T.P. 52, n. ${ }^{\circ} 1$, Madrid, pp. 25 38.

FERNÁNDEZ MURGA, F. (1988): «El rey de Nápoles: las excavaciones arqueológicas». En: Carlos III y la Illustración. Vol. I. Ministerio de Cultura. Madrid, pp. 375-384.

GARCÍA VERDUGO, F. (1992): Córdoba, Burguesía y Urbanismo. Producción y propiedad del suelo urbano: El sector del Gran Capitán, 1859-1936. Gerencia de Urbanismo. Ayuntamiento de Córdoba.

GASCÓ, F. (1994): «Historiadores, falsarios y estudiosos de las antigüedades andaluzas», en J. Beltrán y F. Gascó (eds.): 9-28.

GASCÓ, F.; BELTRÁN, J. (eds.) (1995): La Antigüedad como argumento II. Historiografia de arqueología e historia antigua en Andalucía. Junta de Andalucía. Sevilla.

GLICK, T. F. (1970): «Science and the Revolution of 1868: Notes or the Reception of Darwinism in Spain", en C. Elida y I. M. Zavala (coords.). La Revolución de 1868. Historia, Pensamiento, Literatura. Madrid, pp. 267-272.

GOVERNA, M. V. (1986): «Los estudios de Prehistoria durante la segunda mitad del siglo XIX y primeros años del siglo XX. La obra de Luis Siret", en Homenaje a Luis Siret, Sevilla, pp. 28-34. 
GONZÁLEZ, J. (1994), «Historiografía epigráfica andaluza (siglos XV-XVI)», en J. Beltrán y F. Gascó (eds.): 63-84.

GRAN AYMERICH, E. Y J. (1991): «Les échanges franco-spagnols et la mise en place des institutions archéologiques (1830-1939)", en J. Arce y R. Olmos (coords.): 117-124.

HARRIS, E. C. (1991): Principios de estratigrafía arqueológica, Ed. Crítica, BarceIona.

JIMÉNEZ DÍEZ, J. A. (1993): Historiografía de la pre y protohistoria de la Península Ibérica en el siglo XIX. Universidad Complutense. Tesis doctoral inédita.

KAPLAN, T. (1970): «Positivism and liberalism», en C. Elida y I. M. Zavala (coords). La Revolución de 1868. Historia, Pensamiento, Literatura. Madrid, pp. 254-266.

LÓPEZ ONTIVEROS, A. (1991): La imagen geográfica de Córdoba en la literatura viajera. Cajasur. Córdoba.

LLEÓ CAÑAL. V. (1995): «Origen y función de las primeras colecciones renacentistas de antigüiedades de Andalucía», en F. Gascó y J. Beltrán (eds.): 57-74.

MARAVER, L. (1866-67): «Noticias de los descubrimientos», Rev. de Bellas Artes e Histórico Arq., t. I, n." 30 .

MARCOS POUS, A. (1993): De Gabinete a Museo. Tres siglos de historia. Madrid.

MARTÍN LÓPEZ, C. (1990): Córdoba en el siglo XIX. Modernización de una trama histórica. Gerencia de Urbanismo. Ayuntamiento de Córdoba.

MORA, G. (1991): «Arqueología y poder en la España del siglo XVIII». En J. Arce y R. Olmos (coords.).

MORENO ALONSO, M. (1976), "Historiografia andaluza del sigho XIX (Visión de conjunto)". I Congreso de Historia de Andalucía. Córdoba, pp. 127-135.

- (1979): Historiografia romántica española. Introducción al estudio de la historia en el siglo XIX. Sevilla.

NÚÑEZ RUIZ, D. (1975): La mentalidad positiva en España. Desarrollo y crisis. Madrid.

OLMOS, R. (1992): «Una mirada a la novela arqueológica de raíz decimonónica». Revista de Arqueologia 140. Madrid, pp. 52-57.

PACHÓN, J. A. y PASTOR, M. (1995): «Estudio preliminar» en la ed. facsímil de M. Rodríguez de Berlanga, Los bronces de Osuna y Los nuevos bronces de Osuna (1873-1876), pp. VII-XCII.

PALENCIA CEREZO, J. M. (1995): Setenta años de intervención en el Patrimonio histórico-artístico cordobés (1835-1905). Cajasur. Córdoba. 
PASAMAR, G. y PEIRÓ, I. (1991): «Los orígenes de la profesionalización historiográfica española sobre la Prehistoria y la Antigüedad (tradiciones decimonónicas e influencias europeas)». En J. Arce y R. Olmos (coords.), pp. 73-78.

PASTOR, M. y PACHÓN, J. A. (1991): «Estudio preliminar», en la ed. facsímil de M. de Góngora, Antigüedades prehistóricas de Andalucía (Madrid, 1868). Granada.

PUMAJERO, P. (1990): «Marcelino Sanz de Sautuola», Revista de Arqueología 112. Madrid, pp. 54-56.

QUESADA SANZ, F. (1994): «La Imagen del Héroe. Los antiguos iberos en la plástica española del siglo XIX", Revista de Arqueología 162. Madrid, pp. 37-47.

REPRESA FERNÁNDEZ, M. ${ }^{\mathrm{n}} \mathrm{F}$. (1987): «Las primeras excavaciones borbónicas en Pompeya, Herculano y Stabia (1738-1755)», Revista de Arqueología 78. Madrid, pp. 40-51.

RODRÍGUEZ OLIVA, P. (1991): «Manuel Rodríguez de Berlanga (1825-1909): Notas sobre la vida y la obra de un estudioso andaluz del mundo clásico", en J. Arce y R. Olmos (coords.), pp. 99-106.

SANTOS GENER, S. (1950): Guía del Museo Arqueológico Provincial de Córdoba. Madrid.

SUÁREZ OTERO, J. (1993): «Prehistoria nórdica en el Museo Arqueológico Nacional», en A. Marcos (coord.), pp. 326-334.

TRIGGER, B. G. (1992): Historia del pensamiento arqueológico. Barcelona.

VAQUERIZO, D. (1990): El yacimiento ibérico del Cerro de la Cruz (Almedinilla, Córdoba). Córdoba.

VICENT, A. M.” (1984-85): «Expedición a Fuente Tójar (Córdoba) por L. Maraver», Corduba Archaeologica 15, Bol. del M.A.P. de Córdoba, pp. 31-55. 